Received: 15.08 .2021

Revised: 15.10 .2021

Accepted: 29.10 .2021

DOI: $10.17804 / 2410-9908.2021 .5 .015-023$

\title{
LOW-FREQUENCY RESONANCE IN LAMINATED FeGa-FeCoGa/METGLAS/PZT STRUCTURES
}

\author{
A. P. Nosov*1, 2, a) I. V. Gribov ${ }^{1, \text { b) }}$, N. A. Moskvina ${ }^{1, c)}$, A. V. Druzhinin ${ }^{1, \text { d) }}$, S. S. Dubinin ${ }^{1, \text { e) }}$, \\ V. V. Izyurov ${ }^{1, \text { f) }}$, K. A. Merentsova, g), and M. S. Artemiev ${ }^{1, \text { h) }}$ \\ ${ }^{1}$ M.N. Miheev Institute of Metal Physics, Ural Branch of the Russian Academy of Sciences, \\ 18 S. Kovalevskoi St., Ekaterinburg, 620108, Russian Federation \\ ${ }^{2}$ B. N. Yeltsin Ural Federal University, \\ 19 Mira St., Ekaterinburg, 620002, Russian Federation \\ a) iD http://orcid.org/0000-0003-1475-0059 nossov@imp.uran.ru; \\ b) iD http://orcid.org/0000-0002-5067-2281 gri@imp.uran.ru; \\ c) (iD http://orcid.org/0000-0003-4285-0399 nat@imp.uran.ru; \\ d) (iD http://orcid.org/0000-0001-9944-096X druzhinin@imp.uran.ru; \\ e) (iD http://orcid.org/0000-0003-4937-8496 هubinin_S_S@imp.uran.ru; \\ f) $\otimes$ iziurov.1994@imp.uran.ru; \\ g) $\otimes$ merencovak@mail.ru; \\ h) $\otimes$ cccp9697@mail.ru \\ *Corresponding author. E-mail: nossov@imp.uran.ru \\ Address for correspondence: 18 ul. S. Kovalevskoi, 620108, Ekaterinburg, Russia \\ Tel.: +7 (343) 37479 22; fax: +7 (343) 3745244
}

The paper studies the influence of the composition of a thin-film composite magnetostrictive ferromagnet on the magnetoelectric effect (ME) in ferromagnet/piezoelectric/ferromagnet laminated trilayers at resonant frequencies. The PZT material was used in the piezoelectric layer. The graded composite magnetostrictive ferromagnet with a thickness gradient of the magnetostriction coefficient was obtained by pulsed laser deposition of thin $\mathrm{Fe}_{0.72} \mathrm{Ga}_{0.28}$ or $\mathrm{Fe}_{0.62} \mathrm{Co}_{0.19} \mathrm{Ga}_{0.19}$ films on the surface of Metglas-type 440A amorphous ribbons. The ME was investigated at resonant frequencies of 3 and $9.32 \mathrm{kHz}$. It is shown that the maximum ME value increases with frequency. The deposition of magnetostrictive thin films decreases the maximum ME value, but increases the Q-factor. The results can be useful for developing sensors of static and low-frequency magnetic fields for magnetic nondestructive testing applications under resonant excitation conditions.

Keywords: magnetic field sensor, resonance, amorphous alloy, thin films, magnetoelectric effect, magnetic nondestructive testing.

\section{Acknowledgment}

The research was carried out under the state assignment from the Ministry of Science and Higher Education of the Russian Federation (theme Function, No. AAAA-A19-119012990095-0). The scientific equipment installed at the Testing Center of Nanotechnology and Advanced Materials collaborative access center (IMP UB RAS) was used in the study.

\section{References}

1. Srinivasan G. Magnetoelectric composites. Annual Review of Materials Research, 2010, vol. 40, pp. 153-178. DOI: 10.1146/annurev-matsci-070909-104459.

2. Tech. Bulletin ref. 2605SA106192009, Metglas Inc., Conway, SC, 2009. 
3. Petrov V.M. and Srinivasan G. Enhancement of magnetoelectric coupling in functionally graded ferroelectric and ferromagnetic bilayers. Phys. Rev. B, 2008, vol. 78, 184421 (8 p.). DOI: 10.1103/PhysRevB.78.184421.

4. Nosov A.P., Gribov I.V., Moskvina N.A., Druzhinin A.V., Osotov V.I., Loginov B.A. Magnetoelectric effect in laminate structures with composite magnetostrictive layers based on amorphous tape/thin film Fe-Co-Ga structures. Mezhdunarodnyi Zhurnal Prikladnykh i Fundamentalnykh Issledovaniy, 2016, No. 4, pp. 880-883. (In Russian).

5. Petrie J.R., Fine J., Mandal S., Sreenivasulu G., Srinivasan G. Enhanced sensitivity of magnetoelectric sensors by tuning the resonant frequency. Appl. Phys. Lett., 2011, vol. 99, 043504 (3 p.). DOI: 10.1063/1.3617428.

6. Available at: http://www.gammamet.ru/index.php/ru/informatsiya

7. Jen S.U., Tsai T.L., Kuo P.C., Chi W.L., and Cheng W.C. Magnetostrictive and structural properties of FeCoGa films. J. Appl. Phys., 2010, vol. 107, 013914 (4 p.). DOI: 10.1063/1.3284962. 
Подана в журнал: 15.08.2021

УДК 537.633.9

DOI: $10.17804 / 2410-9908.2021 .5 .015-023$

\title{
НИЗКОЧАСТОТНЫЙ РЕЗОНАНС В ЛАМИНАТНЫХ СТРУКТУРАХ FeGa-FeCoGa/AMOРФНАЯ ЛЕНТА/PZT
}

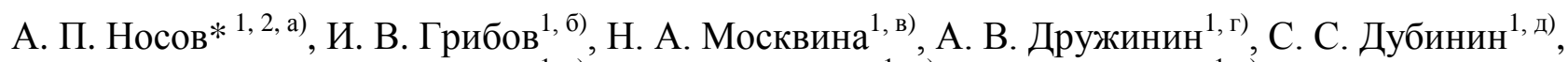 \\ В. В. Изюров ${ }^{1, \text { е) }}$, К. А. Меренцова ${ }^{1, \text { ж) }}$, М. С. Артемьев ${ }^{1,3)}$
}

${ }^{1}$ Институт физики металлов имени М.Н. Михеева Уральского отделения Российской академии наук, ул. С. Ковалевской 18, Екатеринбург, 620108, Российская Федерация

${ }^{2}$ Федеральное государственное автономное образовательное учреждение высшего образования «Уральский федеральный университет имени первого Президента России Б.Н. Ельцина», ул. Мира 19, Екатеринбург, 620002, Российская Федерация

a) iD http://orcid.org/0000-0003-1475-0059 nossov@imp.uran.ru;

б) iD http://orcid.org/0000-0002-5067-2281 gri@imp.uran.ru;

в) (ID http://orcid.org/0000-0003-4285-0399 nat@imp.uran.ru;

г) (iD http://orcid.org/0000-0001-9944-096X ه druzhinin@imp.uran.ru;

д) (iD http://orcid.org/0000-0003-4937-8496 هubinin_S_S@imp.uran.ru;

e) $\otimes$ iziurov.1994@imp.uran.ru;

ж) merencovak@mail.ru;

3) $\otimes$ ccp9697@mail.ru

*Ответственный автор. Эл. почта: nossov@imp.uran.ru

Адрес для переписки: ул. С. Ковалевской 18, Екатеринбург, 620108, Российская Федерация Тел.: +7 (343) 3747922; факс: +7 (343) 3745244

Исследовано влияние состава тонкопленочного композитного магнитострикционного ферромагнетика на магнитоэлектрический эффект (МЭ) на резонансных частотах трехслойных ламинатных структур типа ферромагнетик-пьезоэлектрик-ферромагнетик. В качестве пьезоэлектрика использованы пластины пьезокерамики PZT. Композитный магнитострикционный ферромагнетик с градиентом коэффициента магнитострикции по толщине слоев получали импульсным лазерным осаждением тонких пленок составов $\mathrm{Fe}_{0,72} \mathrm{Ga}_{0,28}$ или $\mathrm{Fe}_{0,62} \mathrm{Co}_{0,19} \mathrm{Ga}_{0,19}$ на поверхность аморфных лент 440А типа «Метглас». Представлены результаты экспериментальных исследований МЭ на частотах резонансного возбуждения 3 и 9,32 кГц. Показано, что максимальная величина МЭ растет с частотой. При этом нанесение магнитострикционных пленок уменьшает величину эффекта, но увеличивает добротность. Результаты могут представлять интерес при создании резонансных датчиков статических и низкочастотных магнитных полей для неразрушающего контроля.

Ключевые слова: датчик магнитного поля, резонанс, аморфный сплав, тонкие пленки, магнитоэлектрический эффект, магнитный неразрушающий контроль.

\section{1. Введение}

Возможность выявления дефектов приборами и устройствами магнитного неразрушающего контроля прежде всего определяется чувствительностью используемых датчиков магнитных полей. В последние годы пристальное внимание исследователей привлек магнитоэлектрический эффект (МЭ) в трехслойных ламинатных структурах типа магнитострикционный ферромагнетик-пьезоэлектрик-магнитострикционный ферромагнетик [1]. При приложении к такой структуре статического $H$ и переменного $d H_{a c}$ магнитных полей под действием магнитострикции ферромагнитного слоя возникнет механическая деформация, 
которая приводит к возникновению электрического поля $d E$ в пьезоэлектрическом слое. Чувствительность к магнитному полю определяют магнитоэлектрическим коэффициентом по напряжению (МЭКН или MEVC), который определяют, как $\alpha=d E / H_{a c}=d V /\left(t d H_{a c}\right)$, где $d V-$ величина возникающего электрического напряжения; $t$ - толщина пьезоэлектрического слоя. Величина $\alpha$ определяется как физическими характеристиками магнитострикционного ферромагнитного слоя, а именно пьезомагнитным коэффициентом $q=d \lambda / d H$, где $\lambda-$ коэффициент магнитострикции, так и характеристиками пьезоэлектрического слоя: пьезомодулем $d$ и относительной диэлектрической проницаемостью $\varepsilon$.

Для решения задач неразрушающего контроля необходимы структуры с максимально большим значением МЭКН. Это может быть достигнуто за счет оптимизации как магнитострикционной, так и пьезоэлектрической подсистем.

Широкое применение в композитных МЭ ламинатных структурах находят аморфные ленты сплавов класса «Метглас» (Metglas) [2]. Эти аморфные магнитные материалы характеризуются большой величиной положительного коэффициента магнитострикции $\lambda$. Кроме того, они имеют большую начальную магнитную проницаемость и малую коэрцитивную силу.

В работе [3] было показано, что если в составе ферромагнитной подсистемы использовать слои магнитострикционных материалов, имеющих разные знаки коэффициента магнитострикции, т. е. создать градиент коэффициента магнитострикции по толщине, то можно увеличить величину $q$. Градиент коэффициента магнитострикции по толщине может быть создан путем напыления на поверхность материала с одним знаком $\lambda$ слоя материала с противоположным знаком коэффициента магнитострикции. Сплавы системы Fe-Ga имеют отрицательный знак $\lambda$. Возможность получения таких структур и их магнитоэлектрические свойства были рассмотрены ранее [4].

Повышение величины МЭКН может быть достигнуто возбуждением пьезоэлектрического слоя на резонансных частотах, при которых выходное напряжение может достигать больших величин. Этот режим работы является стандартным при возбуждении ультразвуковых волн в акустическом неразрушающем контроле. Возможность получения очень больших значений МЭКН на резонансных частотах пьезоэлектрических слоев была продемонстрирована в [5] для структур без градиента коэффициента магнитострикции по толщине слоев. Резонансный режим возбуждения кантилеверов находит широкое использование в сканирующей зондовой микроскопии и микросенсорике. На основе этого режима работы возможна реализация датчиков широкого класса физических величин (массы, давления, температуры и т. п.) со сверхвысокой чувствительностью. Преимуществом структур с МЭКН является дополнительная возможность управления свойствами посредством приложения магнитного поля.

В работе исследован МЭКН в ламинатных структурах ферромагнетик-пьезоэлектрикферромагнетик со слоями ферромагнетика с градиентом коэффициента магнитострикции по толщине в условиях резонансного возбуждения пьезоэлектрического слоя. Ферромагнитные слои с градиентом коэффициента магнитострикции по толщине получали нанесением тонких слоев сплавов $\mathrm{Fe}_{0.72} \mathrm{Ga}_{0.28}$ и $\mathrm{Fe}_{0,62} \mathrm{Co}_{0,19} \mathrm{Ga}_{0,19}$ на поверхность аморфной ленты методом импульсного лазерного осаждения. Исследовано влияние состава слоев на значения МЭКН на разных резонансных частотах.

\section{2. Материал и методика}

В качестве материала пьезоэлектрического слоя ламинатных структур были использованы пластины пьезокерамики марки PZT (\#851) производства компании APC International, Пенсильвания, США. На пластины были нанесены контактные электроды. Были использованы пластины с типичными размерами длина; - 20 мм; ширина - 3 мм; толщина - 0,2 мм.

В качестве магнитострикционного слоя с положительным коэффициентом магнитострикции использовали аморфные ленты состава 440А [6] производства компании «Гамма- 
мет» (г. Екатеринбург, Россия) толщиной 34 мкм. Аморфные ленты использовали в состоянии поставки без дополнительных термообработок. Этот состав характеризуется высокой температурой Кюри $\left(420{ }^{\circ} \mathrm{C}\right)$, индукцией насыщения $1,5 \times 10^{4} \Gamma$ с, максимальной магнитной проницаемостью до 200 000, коэрцитивной силой 0,05 Э. Магнитострикцию измеряли с использованием тензодатчика при ориентациях статического магнитного поля $H$ вдоль $\left(\lambda_{11}=\right.$ $\left.+20 \times 10^{-6} / Э\right)$

и поперек $\left(\lambda_{12}=-15 \times 10^{-6} / Э\right)$ направления прокатки ленты. Величину пьезомагнитного коэффициента определяли как $q=q_{11}+q_{12}=d \lambda_{11} / d H+d \lambda_{12} / d H$ и для использованных лент она составляла $q=+0,46 \times 10^{-6} / \ni$.

Образцы объемных сплавов составов $\mathrm{Fe}_{0,72} \mathrm{Ga}_{0,28}$ и $\mathrm{Fe}_{0,62} \mathrm{Co}_{0,19} \mathrm{Ga}_{0,19}$ получали дуговой плавкой в атмосфере аргона. Сплавы этих составов характеризуются большими отрицательными значениями коэффициента магнитострикции, величина которого максимальна для концентраций галлия 0,19 или 0,28. Легирование сплавов системы $\mathrm{FeGa}$ кобальтом увеличивает $\lambda$. Для тонких пленок сплавов системы FeCoGa значение $\lambda$ максимально у состава $\mathrm{Fe}_{0,62} \mathrm{Co}_{0,19} \mathrm{Ga}_{0,19}[7]$.

Композитные слои с градиентом коэффициента магнитострикционные по толщине получали методом импульсного лазерного осаждения путем нанесения на поверхность аморфных лент тонких пленок составов $\mathrm{Fe}_{0,72} \mathrm{Ga}_{0,28}$ или $\mathrm{Fe}_{0,62} \mathrm{Co}_{0,19} \mathrm{Ga}_{0,19}$ толщиной 25 нм. Использовался эксимерный лазер CL 7050 (компания «Оптисистемы», г. Троицк, Московская обл., Россия). Измерения толщины и шероховатости поверхности производили с использованием оптического профилометра ZYGO.

Объектами исследований были трехслойные ламинатные структуры, в которых в качестве верхнего и нижнего слоев использовали аморфные магнитострикционные ленты, наклеенные на пьезопластину клеем на основе цианокрилата. Толщина слоя клея в готовой структуре не превышала 2 мкм. Использование трехслойных структур вместо двухслойных позволяет увеличить величину МЭКН. Были приготовлены структуры со слоями из аморфной ленты 440A без тонких пленок (далее - образцы 440A), со слоями из ленты 440А с нанесенной тонкой пленкой $\mathrm{Fe}_{0,72} \mathrm{Ga}_{0,28}$ (далее - образцы $440 \mathrm{~A} / \mathrm{FeGa}$ ), а также со слоями из ленты 440A с нанесенной тонкой пленкой $\mathrm{Fe}_{0,62} \mathrm{Co}_{0,19} \mathrm{Ga}_{0,19}$ (далее - образцы 440A/FeCoGa).

Измерения МЭКН выполняли в условиях приложения к структурам статического $H$ и низкочастотного переменного $H_{a c}$ магнитных полей, ориентированных в плоскости образца. Использовалась геометрия кантилевера: в процессе измерений один конец образца был жестко закреплен, а второй оставался свободным. Аморфные ленты покрывали всю ширину свободного конца образца. Отношение длины аморфной ленты к длине незакрепленной части пьезопластины составляло 0,47 . Напряжение в пьезоэлектрическом слое $d V$ измеряли синхронным детектором на частоте $H_{a c}$. Величину МЭКН вычисляли по формуле $\alpha=d E / H_{a c}=d V /\left(t d H_{a c}\right)$, где $t$ - толщина пьезоэлектрического слоя. Исследовали зависимости $\alpha$ от величины статического магнитного поля $H$ и частоты $f$ низкочастотного переменного магнитного поля. Все измерения проводили при комнатной температуре.

\section{3. Результаты и обсуждение}

На рис. 1 представлены типичные зависимости МКЭН от величины приложенного статического поля $\alpha\left(H_{d c}\right)$, снятые на частоте $f=3$ кГц. Для всех частот зависимости имеют сходную форму с максимумом при $H_{d c} \approx 30$ Э. Положение этого максимума соответствует максимуму зависимости $q\left(H_{d c}\right)$ и незначительно изменяется с изменением состава магнитострикционного слоя. Для всех зависимостей значения $\alpha$ постепенно уменьшаются с ростом $H_{d c}>40$ Э. Из приведенных данных следует, что нанесение тонких пленок уменьшает максимальную величину $\alpha$, причем состав наносимой пленки сравнительно слабо влияет на величину эффекта в максимуме. 


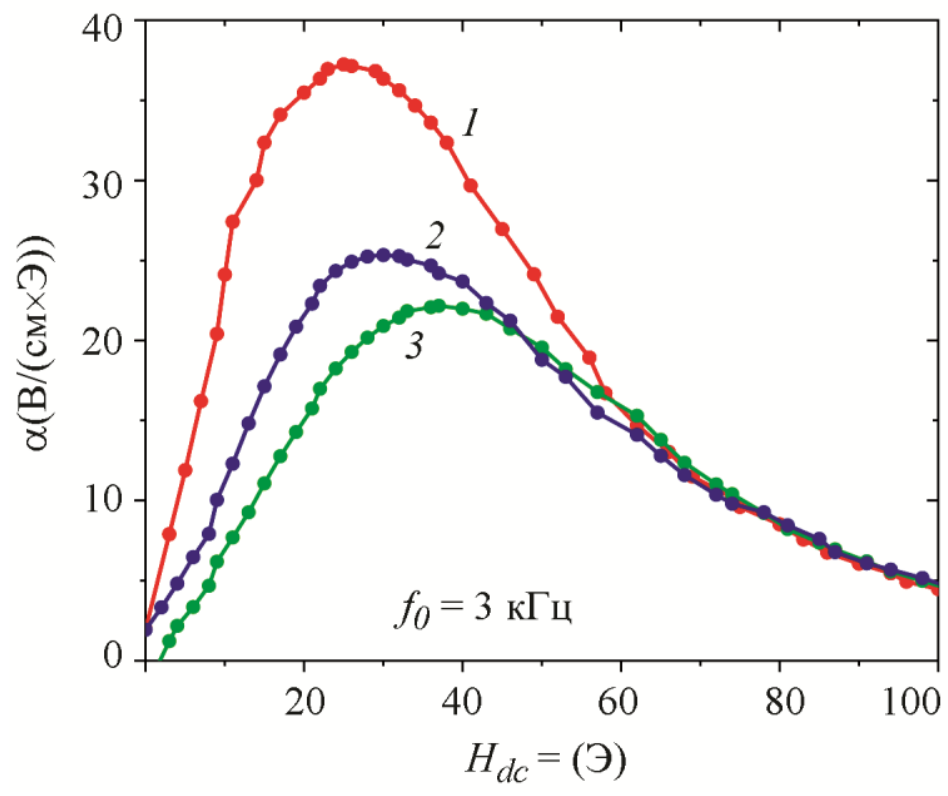

Рис. 1. Сравнение полевых зависимостей МЭКН на частоте $f_{0}=3$ кГц для ламинатных структур с магнитострикционными слоями только из аморфной ленты (1 - 440A), из аморфных лент с пленками $\mathrm{Fe}_{0,72} \mathrm{Ga}_{0,28}(2-\mathrm{FeGa})$ и $\mathrm{Fe}_{0,62} \mathrm{Co}_{0,19} \mathrm{Ga}_{0,19}(3-\mathrm{FeCoGa})$

Рис. 2 иллюстрирует резонансную частотную величины $\alpha(f)$ в поле $H_{d c} \approx 37$ Э и отсутствие ее в нулевом поле.

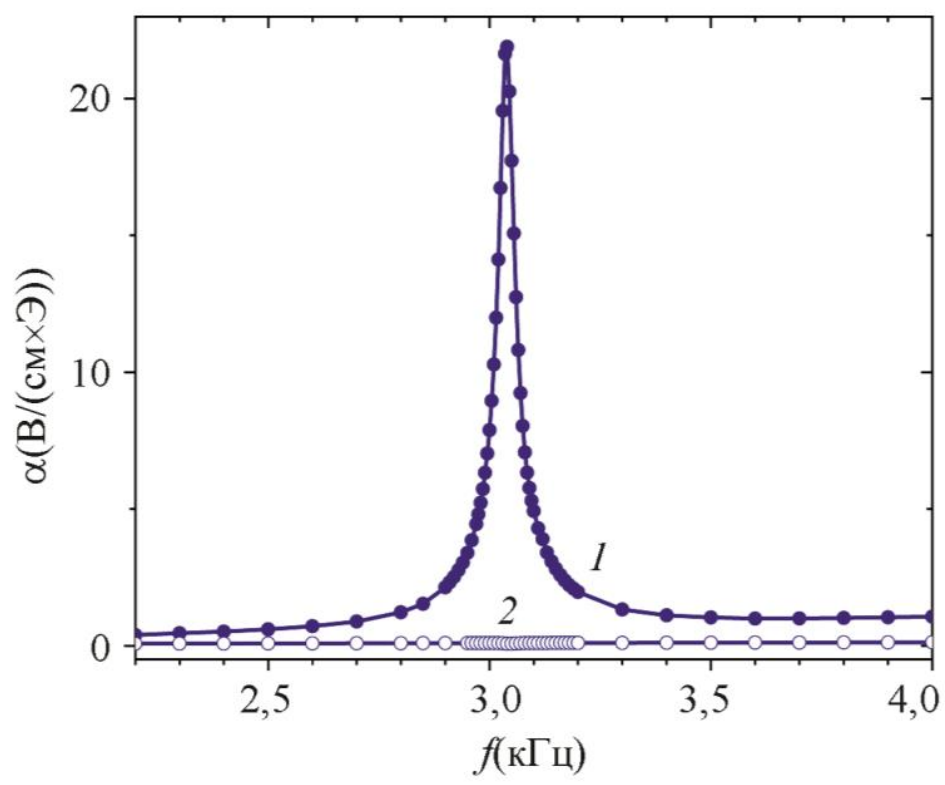

Рис. 2. Частотная зависимость МЭКН для ламинатной структуры

с магнитострикционными слоями из аморфной ленты с пленкой $\mathrm{Fe}_{0,62} \mathrm{Co}_{0,19} \mathrm{Ga}_{0,19}$ при $H_{d c} \approx 37$ Э -1 и в нулевом поле -2

Для структуры со слоями из аморфной ленты 440А без тонких пленок повышение резонансной частоты до $f=9,32$ кГц приводит росту максимальной величины МКЭН в 2,57 раза (рис. 3). При этом максимум наблюдается при тех же значениях $H_{d c} \approx 30$ Э, что и на частоте 3 кГц. Увеличение максимальной величины МКЭН наблюдается и для структур с тонкими пленками. При этом состав пленок практически не оказывает влияния на максимальную величину эффекта. 


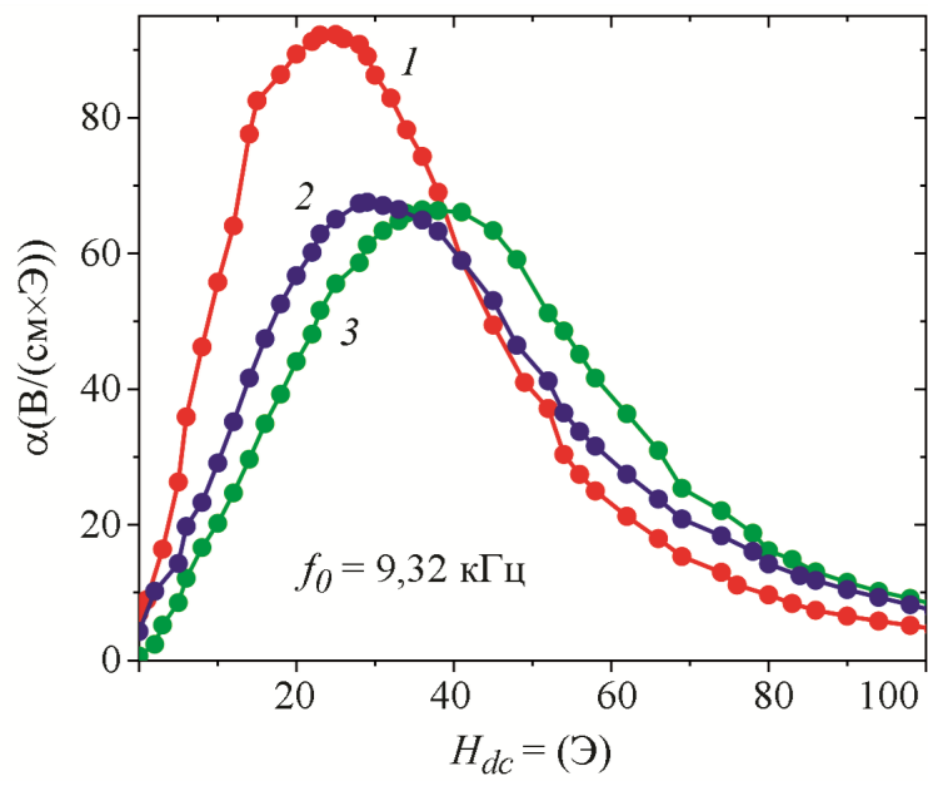

Рис. 3. Сравнение полевых зависимостей МЭКН на частоте $f_{0}=9,32$ кГц для ламинатных структур с магнитострикционными слоями только из аморфной ленты $(440 \mathrm{~A}-1)$, из аморфных лент с пленками $\mathrm{Fe}_{0,72} \mathrm{Ga}_{0,28}(\mathrm{FeGa}-2)$ и $\mathrm{Fe}_{0,62} \mathrm{Co}_{0,19} \mathrm{Ga}_{0,19}(\mathrm{FeCoGa}-3)$

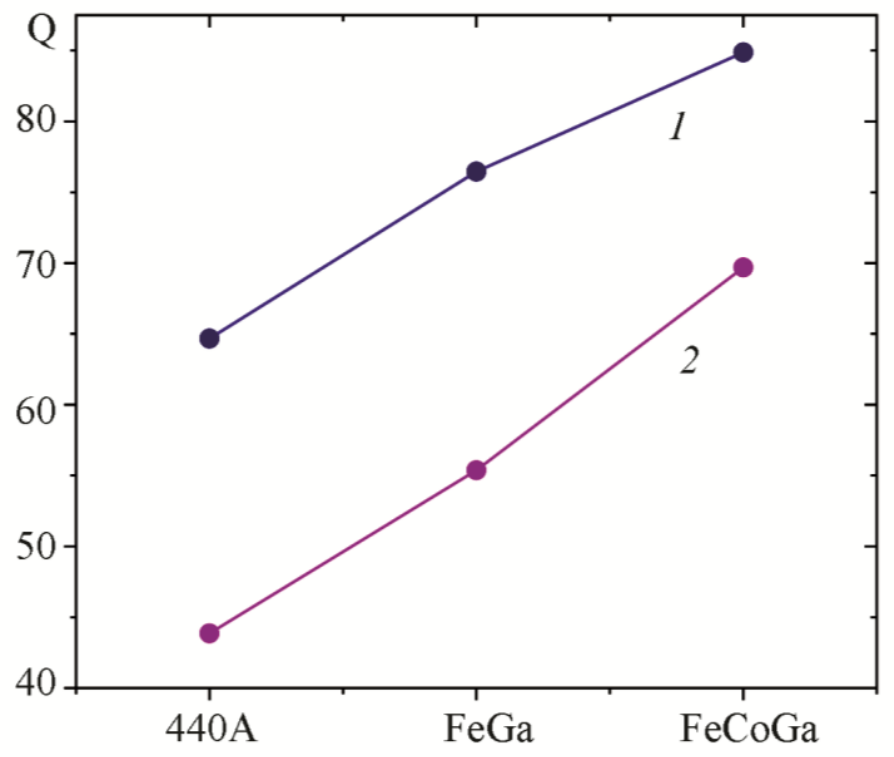

Рис. 4. Сравнение добротности резонансных зависимостей на частотах:

1 - 9,32 кГц; 2 - 3 кГц для ламинатных структур с магнитострикционными слоями только

с аморфной лентой (440A) и аморфными лентами с пленками $\mathrm{Fe}_{0,72} \mathrm{Ga}_{0,28}(\mathrm{FeGa})$ и $\mathrm{Fe}_{0,62} \mathrm{Co}_{0,19} \mathrm{Ga}_{0,19}(\mathrm{FeCoGa})$

Однако состав пленок оказывает существенное влияние на добротность резонансных кривых (рис. 4). Из приведенных данных следует, что добротность существенно возрастает при нанесении пленок, причем максимальной добротностью характеризуется структура со слоем $\mathrm{Fe}_{0,62} \mathrm{Co}_{0,19} \mathrm{Ga}_{0,19}$. Величина добротности сильно увеличивается с частотой.

Это обстоятельство может быть важным преимуществом при использовании композитных магнитоэлектрических ламинатных структур с градиентом магнитострикционных свойств по толщине ферромагнитного слоя в потенциальных приложениях, использующих возбуждение на резонансных частотах, поскольку чем выше добротность, тем 
лучше избирательные свойства колебательного контура, в составе которого может быть использована структура.

В целом следует отметить, что при резонансном возбуждении трехслойных ламинатных структур типа тонкопленочный композитный магнитострикционный ферромагнетик-пьезокерамика PZT-тонкопленочный композитный магнитострикционный ферромагнетик создание градиента коэффициента магнитострикции по толщине ферромагнитного слоя за счет нанесения на поверхность аморфных лент 440А тонких пленок $\mathrm{Fe}_{0,72} \mathrm{Ga}_{0,28}$ и $\mathrm{Fe}_{0,62} \mathrm{Co}_{0,19} \mathrm{Ga}_{0,19}$ не улучшает максимальную величину МЭКН, однако повышает добротность структуры в целом при использовании состава $\mathrm{Fe}_{0,62} \mathrm{Co}_{0,19} \mathrm{Ga}_{0,19}$.

\section{4. Заключение}

Исследованы полевые и частотные характеристики магнитоэлектрического эффекта по напряжению в условиях резонансного возбуждения ламинатных структур типа тонкопленочный композитный магнитострикционный ферромагнетик /пьезокерамика PZT/ тонкопленочный композитный магнитострикционный ферромагнетик, полученных лазерным осаждением тонких пленок $\mathrm{Fe}_{0,72} \mathrm{Ga}_{0,28}$ и $\mathrm{Fe}_{0,62} \mathrm{Co}_{0,19} \mathrm{Ga}_{0,19}$ с отрицательным коэффициентом магнитострикции на аморфные ленты типа «Метглас» с положительным коэффициентом магнитострикции. Композитная ферромагнитная подсистема с такой структурой характеризуется градиентом коэффициента магнитострикции по толщине слоев. Для фиксированной частоты возбуждения использование композитных слоев не приводит к увеличению МКЭН. Экспериментально показано, что МЭКН существенно увеличивается с ростом частоты возбуждения. Нанесение тонких пленок существенно улучшает добротность, которая также растет с частотой. Наибольшими значениями добротности характеризуются слои с тонкими пленками $\mathrm{Fe}_{0,62} \mathrm{Co}_{0,19} \mathrm{Ga}_{0,19}$. Исследованные ламинатные структуры могут представлять интерес для разработки высокочувствительных датчиков статических и низкочастотных магнитных полей с резонансным возбуждением для приборов и устройств магнитного неразрушающего контроля.

\section{Благодарность}

Работа выполнена в рамках государственного задания Минобрнауки России (тема «Функиия», № AAAA-A19-119012990095-0).

Работа выполнена с использованием оборудования ЦКП «Испытательный иентр нанотехнологий и перспективных материалов» ИФМ УрО РАН.

\section{Литература}

1. Srinivasan G. Magnetoelectric composites // Annual Review of Materials Research. - 2010. Vol. 40. - P. 153-178. - DOI: 10.1146/annurev-matsci-070909-104459.

2. $\quad$ Tech. Bulletin ref. 2605SA106192009. - Metglas Inc., Conway, SC, 2009.

3. Petrov V. M. and Srinivasan G. Enhancement of magnetoelectric coupling in functionally graded ferroelectric and ferromagnetic bilayers // Phys. Rev. B. - 2008. - Vol. 78. - P. 184421. DOI: 10.1103/PhysRevB.78.184421.

4. Носов А. П., Грибов И. В., Москвина Н. А., Дружинин А. В., Осотов В. И., Логинов Б. А. Магнитоэлектрический эффект в ламинатных структурах с композитными магнитострикционными слоями на основе структур аморфная лента/тонкая пленка $\mathrm{Fe}-\mathrm{Co}-\mathrm{Ga} / /$ Международный журнал прикладных и фундаментальных исследований. 2016. - № 4. - C. 880-883.

5. Enhanced sensitivity of magnetoelectric sensors by tuning the resonant frequency / J. R. Petrie, J. Fine, S. Mandal, G. Sreenivasulu, G. Srinivasan // Appl. Phys. Lett. - 2011. - Vol. 99. P. 043504. - DOI: 10.1063/1.3617428. 
6. URL: http://www.gammamet.ru/index.php/ru/informatsiya

7. Magnetostrictive and structural properties of FeCoGa films / S. U. Jen, T. L. Tsai, P. C. Kuo, W. L. Chi, and W. C. Cheng // J. Appl. Phys. - 2010. - Vol. 107. - P. 013914. DOI: $10.1063 / 1.3284962$. 